\section{COMPLETE INVERSION OF THE URINARY BLADDER.}

BY

\section{BURGOYNE PASLEY, F.R.C.S.I.,} CHIEF SURGEON, FEDERATED MALAY STATES.

Comprete inversion of the urinary bladder is a condition of such extreme rarity that the publication of the clinical details in such a case would seem to be warranted.

An undersized, rather poorly nourished Clinese girl, aged 15, with a facies suggestive of hereditary syphilis, and mentally very stupid, was admitted to hospital on August 10th, 1927.

History.-About two months previously the patient had noticed " small and tender swelling between the vulvae; this she had "pushed back." There was apparently a recurrence some five weeks later. About two days before her admission she was carrying two heavy casks of water when she felt something "give." (n reaching home she found a large mass between the vulvae. On the following day she remained in bed and attempted to push back the mass, but failed.

On admission to hospital she was seen and examined by the lady medical oflicer, Dr. Hewitson, who concluded that the protruding mass was possibly the urinary bladder. Shortly afterwards I saw her, and, under chloroform anaesthesia, made a thorough examination.

Condition on Almission.-I found that the protruding mass was without doubt the entire urinary bladder inverted. The mucous membrane was intensely red and inflamed, bleeding on palpation. On gently raising the inass uine could be seen flowing from the ureteral orifices, which were visible just inside the posterior margin of the enormously dilated uretlura. Vinside the posterior tion showed that the hymen was absent, the cervix normal, and the uterus small and normally placed. The anterior fornix was obliterated.

Having thoroughly cleansed the parts with warm sterile saline, I returned the protruding mass by steady and gentle pressure, Digital examination proved that no growth of any sort was present. The urethra easily admitted my thumb. The patient was put to bed with buttocks raised, and for a few days the bladder was washed out with 1 in 2,000 acriflavine. She was kept in the recumbent position for three weeks, by the end of which time she seemed able to retain her urine.

At her own request she was permited to leave hospital, and was instructed to return at once should inversion recur. During her stay in hospital her pulse and temperature remained

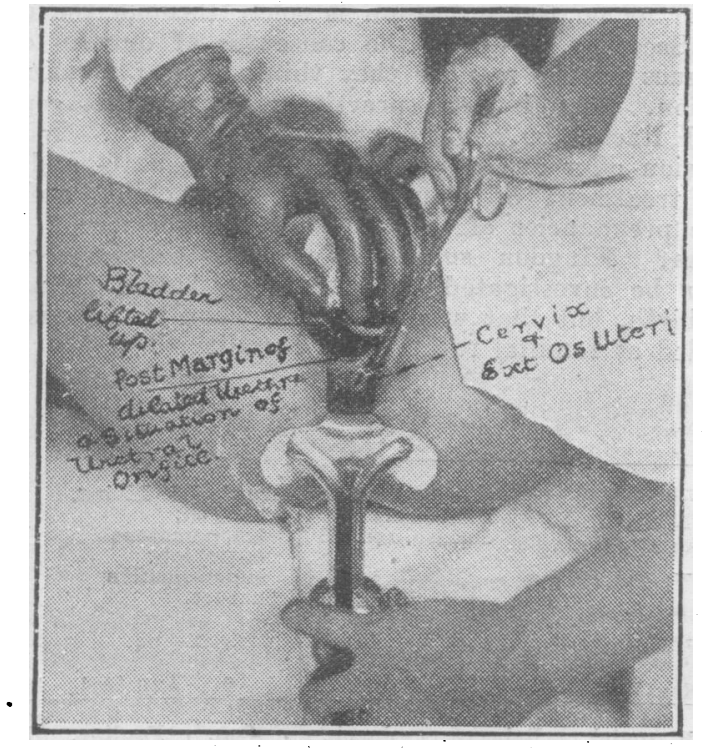

normal; the urine also was normal. I was most disappointed not to have been able at this time to obtain photographs of the condition.

The patient was readmitted to hospital on September 23rd suffering from bronchitis and subtertian malaria. The next day I was sent for, as, following a severe fit of coughing, the bladder had again inverted. She was anaesthetized and pholographs were obtained which clearly showed the conditions present.

The bladder was again replaced and the patient was returned to bed, quinine in 10-grain doses being ordered.

It seemed evident that some form of operation was required to prevent furtiner recurrence. A scarch through all arailable literature failed to give any information, save an article entitled "Prolapse of urethra in female children," by Thomas N. Hepburn, F.A.C.S., published in the American Journal of Surgery for March, 1927 (p. 400), wherein the writer very clearly describes an operation. I letermined to try a similar technique.

On October 10th, under general anaesthesia, the space of Retzius was freely opened up. The peritoneal reflection from the anterior surface of the bladder was defined and the bladder was defined and
drawn upwards. The bladder drawn upwards. The bladder rubber-protected forceps and drawn upwards. The posterior aspect of the symphysis pubis was lightly scarified. The anterior surface of the neck of the bladder was rubbed with gauze and then firmly sutured to the pubis. The wound was closed without drainage, and lry dressings were applied. It was noticed that this procedure had the effect of clrawing. up the urethra, which before opera-

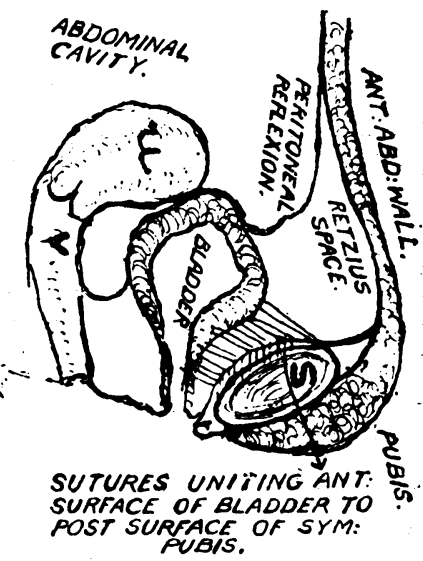

ion was pouching.

The patient suffered from considerable post-operative romiting, but no sign of prolapse of the urethra or bladder occurred.

It will be interesting to see if this operation cures the condition. I should be thankful for any information bearing on the case, both as regards incidence, causes, and treatment.

\section{A CHYLOUS MESENTERIC CYST. \\ BY}

GILBERT. I. WILSON, B.M., B.CH.Oxon., F.R.C.S.ED.

LATE SENIOR HOUSE-SURGEON, MANSFIELD AND DISTRICT HOSPITAL, NOTTS.

THE following case is noteworthy on account of its.rarty, and $\partial f$ the satisfactory immediate result of conservative operative treatment.

$A$ boy, aged 8, was admitted to Mansfield Hospital on April 3rd, 1928, from a neighbouring sanatorium "for relief by laparotomy 1928 , from a neighbouring sanatorium ",
of ascites due to tuberculous peritonitis."

of ascites due to tuberculous peritonitis."
The first symptoms had been noticed two years previously. The boy was developing a ravenous appetite, especially marked in the early pa:t of the day, and was unusually sleepy in the evening. $\mathrm{He}$ would "eat all day"-a mixed diet with an excess of bread, butter, and potatoes--and then sleep ten or eleven hours each inight. Shortly after this the abdomen was observed to be rather night. Shor ary much more marked during tho large, but the increase had been much more marked the the boy last six months, and bowels were opened cach morning urgently became thin. The bowels were opened cach morning urgently in the stools. The boy played games, and his gencral health remained fairly good.

Previous io these symptoms he had been an exceptionally healthy child, being $11 \mathrm{lb}$. at birth, and but slightly troubled by measles and chicken-pox. When 6 years old (six months before any-
thing of the present trouble was noticed) he broke his leg, thing of the present trouble was noticed) he broke his leg, but nó conco
rememberéd.

Condition on Admission.-The patient was very thin. No irregucor very large abdomen, but percussion larites were palpated regilical regas as duil as the talks, tho revealed that the umbilical region was as duil as the tranks, tho only resonant area being in the epigastriun

Opcration.-The abdomen was opened through a subumbilical incision, but no fluid was found. Across a soft, white, cystic swelling was stretched a band of small gut, rather bluish in swelling was stretched a band of small gut, rather bluish in colour. By palpation the swelling was found to extend upwarits, pushing the transverse colon, great omentum, and stomach welf up under the diaphragm. Laterally the cyst extended behind botly in the flanks, thereby becoming trilocular, but all parts communicated freely. In the pelvis were coils of gut. The cyst wall was uniform, and by pinching it was found to be extraordinarily thin. The contents appeared to be opalescent in thin layers, white in thicker, and a diagnosis of chylous mesenteric cyst was arrived at small opening was made, and four and a half pints of at. A small opening was made, and four and a resembling milk, was drained off. The opening was fluid, exactly resembling milk, was drained off. The opening was closed by ligature, the cyst wall being so thin that the finest stiteh holes causer leaks. A certain quantity of fluid was left
behind, probably less than a pint. The abdomen was closed. Convalescence was uneventful, 
Analysis of the fluid gave the following main facts: specific gravity 1,013; faintly alkaline; total solids 9.58 per cent.-ash 0.9 per cent. (sodium chloride, trace of potash and phosphates), fat 4.05 per cent., protein 3.50 per cent. (almost wholly serum globulin and albumin); there were traces of blood cells, with an excess of mononuclear types; no organisms were found. This is within the limits of composition of pure chyle. The fat was in a very finely divided state, a many times finer emulsion than cow's milk.

Subscqucnt Progress.-The boy left for home on the sixteenth day, a detailed diet having been prescribed, largely, but not wholly, fat-free. He was a most depressing sight-pinched face, splayed-out ribs over a flaccid, rather scaphoid, abdomen, and match-like legs. Five weeks later (May 22nd, 1928) the change in the child surprised me, and I regretted not having taken the weight (now 4 st. $3 \frac{1}{2}$ lb.) and the waist measurement (now 26 in.) previously. The thorax and abdomen were within normal limits of shape, a moderate layer of subcutaneous fat had appeared, and the boy was now of lively disposition. The clinical signs of cyst or fluid were doubtfully obtainable.

Nine weeks later (July 28th, 1928) the weight was 4 st. $5 \frac{1}{4} \mathrm{lb}$. and the waisto $26 \frac{1}{4}$ in. There seemed now to be definite evidence of a flaccid cyst in the abdomen, and I should think that the fluid is collecting again very slowly.

In discrussing the probable origin of the cyst I must express my great indebtedness to Dr. G. Payling Wright of University College Hospital for references to the literature and many suggestions of practical value.

The cyst may be classed broadly as mesenteric, and may, therefore, be primarily chylous, or due to an effusion of chyle into a preformed cyst. C. N. Dowd reviews the subject, and is of opinion that the latter riew is correct. If this is so, "false" cysts-inflammatory, parasitic, neoplastic, and dermoid-can hardly be applicable to this case, leaving traumatic and "true" mesenteric crsts only to be discussed.

Of the "true" cysts those suspected to be of urogenital (Wolffian) or enteric origin are lined with epithelium (sometimes very flattened), and although this has been described, the present cyst was so thin-walled, and under such low tension, that there can be little doubt that the wall consisted solely of endothelium and the barest supporting framework of areolar and fibrous tissue. Therefore, it would approach the lymphatic cyst (comparable to a cystic hygroma, which it did not in the least resemble), or a mesocolic cyst (formed of lavers of mesentery which failed to fuse after the rotation of the gut in the cimbryo). Theoretically the superficial position of the (yst, lying against the small gut anterior to the mesenteric ressels, fits in with the mesocolic theory, hut I have found no definite evidence that such cysts ever occur.

A traumatic cyst should be associated with adhesions, which were not found. Such cysts are said to occur after a blow on the spine, causing rupture of the receptaculum chyli or thoracic duct. A novel suggestion may be of interest in this connexion-namely, that the condition was one of retroperitoneal effusion of chyle held up by the more firm attachments of the peritonewim to the diaphragmatic, pelvic, and transversalis fascias than to the lumbar and perinephric fascias. However, I have not been able to confirm that these attachments are more firm.

There remains the view that the condition might be primarily chylous-that is, a cystic dilatation of a chylous lymphatic duct, due to obstruction possibly from tramatic or tuberculous fibrosis. This, a simple view at first sight, presents the difficulty that there is such a free anastomosis between ducts; even the entrance to the receptaculum chyli is usually by two or three channels. Had a cure been obtained, the only reasonable explanation would have been that a partial valvular obstruction in a duct had been overcome hy complete relief of tension, but a cure now seems a doubtful possibility.

One can therefore only cousider three likely explanations: (1) effusion into a preformed mesocolic eyst; (2) a true obstructive cystic dilatation; (3) a retroperitoneal effusion. In view of the very extensive nature of the cyst the last view cannot be put aside lightly. Finally, as the condition may require further surgical intervention, suggestions as to procedure and investigation at the time would be of considerable value.

I am indebted to the kindness of Dr. Arthur Humnard for permission to publish this case.

\section{ELECTROTHERAPY IN NON-GONOCOCCAL CERVICITIS.}

\author{
BY
}

C. F. ORR WHITE, M.R.C.S., L.R.C.P., D.M.R.E.,

MEDICAL OFFICER IN CHARGE OF ELECTRO-THERAPEUTIC DEPARTMENT, ROYAL NORTHERN HOSPITAL.

By means of the electrical treatment detailed below it is usually possible to clear up cases of discharge from the cervix and urethra where douches and other means have failed.

In hospital practice diathermy is applied to the cervix and urethra as a routine for the first four sessions, Dr. Cumberbatch's special technique being employed. This kills any gonococci which may remain and stimulates internal secretions to combat toxins, but is not essential in non-gonococcal cases. During the next six sessions a welllubricated zinc or copper electrode an inch and a half long by three-sixteenths of an inch in diameter (at the end of which is placed a circular dise to insulate the parts round the introitus urethrae) is introduced into the urethra; an indifferent pad electrode, eight inches by six, and half an inch thick, soaked in salt solution, being placed over the lower abdomen. The wrethral electrode boing steadied by a suitable stand the cables are comnected to the electrodes and the galyanic current slowly turned on till a strength of 5 to $7 \mathrm{ma}$. is reached. The positive pole is always connected to the urethral elcctrode, and after twenty minutes' treatment the galvanic current is slowly turned off. More than $5 \mathrm{ma}$. should not be used at first as he patient may complain afterwards of pain on micturition.

When treatment of the urethra has been completed a speculum is introduced into the vagina till the cervix is clearly seen, and an electrode of the same shape and material, but a foot in. length, is passed down the speculum and introduced gentIy about threc-quarter's of an inch into the cervix; if endometritis is present it may pass an inch or more. A piece of rubber tubing is slipped orer the electrode as far as the cervix, thus preventing any shortcircuiting with the speculum or possible burn of ine ragina. The indifferent electrode being in position as before, the negative cable is attached to the electrode passing to the cervix and a current of 15 to 25 ma. passed for twenty minutes. This not only causes copious secretion from the cerrical mucous membrane and draining away of pathological products, but has a caustic action as well.

At the last two sessions, by which time the discharge has become less or nearly ceased, the positive cable is applied to the electrode in the cervix, and the current turned on till $40 \mathrm{ma}$. is slowly reached. This current is passed for twenty minutes and slowly turned off. The result is to dry up the cerrical secretion, and at the same time (according to type of electrode used) introduce into the cervix. zinc or copper ions, both of which are strongly antiseptic. The average number of treatments necessary is about a dozen, but this will depend on the amount of cervical and urethral inflammation and induration, which within limits vary with the duration of the discharge. This brings out the importance of early treatment, which makes for a good prognosis. In every such case it is essential to treat the urethra.

I will illustrate the results of treatment by giring two typical cases.

A woman, aged 21, complained of discharge and frequency of micturition (the date of onset was not stated). Treatment was
begun at the Roval Northern Hospital on September 13th, 1926. begun at the Roval Northern Hospital on September 13th, 1926.
On examination the cervix was seen to be congested and indurated, maculae were present on the vulva, and pus exuded from the cervix. A smear showed no gonococci. Only slight improvement followed treatment with silver nitrate douches. She was sent to followed treatment November 15th, 1926. The urethra was swollen, the cervix red and swollen, and thick pus was obtained from both. the cervix red and swollen, and thick pus was obtained from both. Three treatruents by diathermy caused the cervix to become less red and swollen. Ionization was performed weekly till December. cervix or urethra. The patient reported in a fortnight and again in a month, and at the last examination some chronic thickening of the cervix was found, with rather excessive clear mucous discharge, from which the patient had no discomfort whatever. No pus was found, and cultures from the cervix were negative. 